Modelling the effect of corrosion on bond in reinforced concrete

K. Lundgren

Published in Magazine of Concrete Research, see journal homepage http://www.icevirtuallibrary.com/content/journals

"Permission is granted by ICE Publishing to print one copy for personal use. Any other use of these PDF files is subject to reprint fees." 


\title{
Modelling the effect of corrosion on bond in reinforced concrete
}

\author{
Karin Lundgren* \\ Chalmers University of Technology
}

Corrosion of reinforcement leads to a volume increase; thus, splitting stresses are induced in the concrete. Thereby, the bond mechanism between the reinforcement and the concrete is influenced. In order to model the splitting stresses of the corrosion, the mechanical behaviour of the corrosion products must be known. Analyses of corrosion cracking tests led to the assumption that the corrosion products behave like a granular material; i.e. their stiffness increases with the stress level. This mechanical behaviour, and the volume of the rust relative to the uncorroded steel, were given as input for a corrosion layer. This layer was used, together with a model developed earlier for the bond mechanism, in finite element analyses of corrosion cracking tests and pull-out tests with corroded reinforcement. Reasonably good agreement between test results and analyses was obtained. The results show that this method of modelling can predict the decrease of bond when splitting of the concrete occurs, due to the combined action of corrosion and the bond mechanism.

\section{Introduction}

Corrosion of the reinforcement often determines the durability of concrete structures. Since corrosion of reinforcement causes a volume increase, splitting stresses are induced in the concrete. Corrosion is also known to influence the friction between the reinforcement bar and the concrete. These two effects lead to a very strong interaction between corrosion of the reinforcement and the bond mechanism. Furthermore, the bond mechanism between deformed bars and concrete is influenced by a number of other parameters, such as the strength of the surrounding structure, the occurrence of splitting cracks and yielding of the reinforcement. Most of the work done concerning how corrosion affects the bond mechanism is experimental. On the basis of test results, empirical formulae that describe what influence corrosion has on the bond strength have been formulated, see FIB. ${ }^{1}$ However, this approach is most highly dependent upon details such as concrete cover, amount of stirrups, etc. A more general model of how the bond mechanism is affected by corrosion of the steel has not been found in the literature.

\footnotetext{
* Department of Structural Engineering, Concrete Structures, Cha]mers University of Technology, SE-412 96 Göteborg, Sweden.

(MCR 916) Paper received 4 January 2001; last revised 6 July 2001; accepted 3 September 2001
}

In earlier work by the author, ${ }^{2}$ a general model of the bond mechanism was developed. In this bond model, the splitting stresses of the bond action are included, and the bond stress depends not only on the slip, but also on the radial deformation between the reinforcement bar and the concrete. Thereby, the loss of bond at splitting failure or if the reinforcement is yielding can be simulated. This bond model is here combined with the modelling of a corrosion layer. With this method of modelling, one set of input parameters is given for the interface between the steel and the concrete. Depending on the applied corrosion level, and on the confinement of the modelled surrounding structure, various bondslip curves result. The modelling of the combined corrosion and bond layer is presented here, together with results from finite element analyses of corrosion cracking tests and pull-out tests of corroded bars.

\section{Interface elements}

The modelling method described in this article is specially suited for detailed three-dimensional finite element analyses, where both the concrete and the reinforcement are modelled with solid elements. The finite element program DIANA was used. There, interface elements are available which describe a relation between the traction $\mathbf{t}$ and the relative displacement $\mathbf{u}$ 
in the interface. These interface elements are used at the surface between the reinforcement bars and the concrete. The physical interpretations of the variables $t_{n}, t_{t}, u_{n}$ and $u_{t}$ are shown in Fig. 1. The corrosion model and the bond model can be viewed as two separate layers around a reinforcement bar. However, to reduce the number of nodes required to model a structure, they are integrated in one interface element. Due to equilibrium between the two layers, the traction $\mathbf{t}$ is the same in the bond and in the corrosion layer. The deformations are related by

$$
\begin{gathered}
u_{n}=u_{n c o r}+u_{n b o n d} \\
u_{t}=u_{\text {tbond }}, u_{\text {tcor }}=0
\end{gathered}
$$

where the index cor means for the corrosion layer, and the index bond means for the bond layer. Equations (1) and (2) are solved within the interface element, together with the condition for equilibrium. For more information about the implementation, see Lundgren. ${ }^{3}$

\section{Bond model}

\section{Presentation of the bond model}

The model of the bond mechanism is presented in greater detail by Lundgren and Gylltoft, ${ }^{2}$ and by Lundgren. ${ }^{4}$ Here, a brief summary of the model is given. The bond model is a frictional model, using elasto-plastic theory to describe the relations between the stresses and the deformations. The relation between the tractions $\mathbf{t}$ and the relative displacements $\mathbf{u}$ is in the elastic range

$$
\left[\begin{array}{c}
t_{n} \\
t_{t}
\end{array}\right]=\left[\begin{array}{cc}
D_{11} & \frac{\left|u_{\text {tbond }}\right|}{u_{\text {tbond }}} D_{12} \\
0 & D_{22}
\end{array}\right]\left[\begin{array}{l}
u_{\text {nbond }} \\
u_{\text {tbond }}
\end{array}\right]
$$

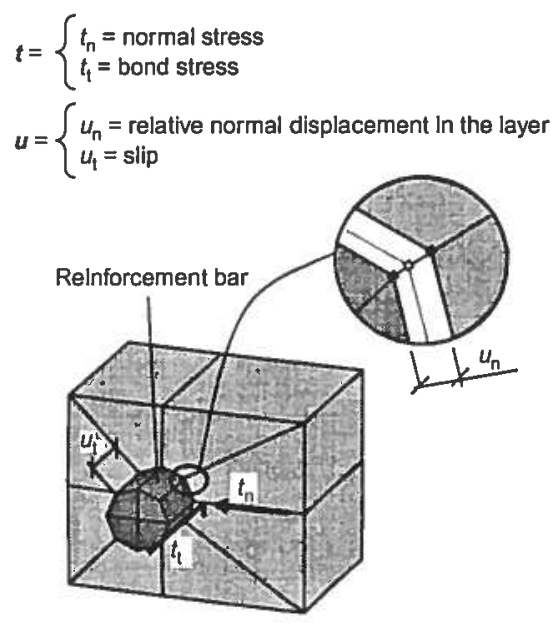

Fig. 1. Physical interpretation of the variables $t_{n}, t_{t}, u_{n}$ and $u$ t where $D_{12}$ normally is negative, meaning that slip in either direction will cause negative $t_{n}$, i.e. compressive forces directed outwards in the concrete. The yield surface is defined by two yield functions, one describing the friction $F_{1}$, assuming that the adhesion is negligible. The other yield function, $F_{2}$, describes the upper limit at a pull-out failure. It is determined from the stress in the inclined compressive struts that results from the bond action.

$$
\begin{gathered}
F_{1}=\left|t_{t}\right|+\mu t_{n}=0 \\
F_{2}=t_{t}^{2}+t_{n}^{2}+c \cdot t_{n}=0
\end{gathered}
$$

The yield surface is shown in Fig. 2. For plastic loading along the yield function describing the upper limit, $F_{2}$, an associated flow rule is assumed. For the yield function describing the friction, $F_{1}$, a non-associated flow rule is assumed, for which the plastic part of the deformations is

$$
d \mathrm{u}^{p}=d \lambda \frac{\partial G}{\partial \mathrm{t}}, \quad G=\frac{\left|u_{\text {tbond }}\right|}{u_{\text {tbond }}} t_{t}+\eta t_{n}=0 .
$$

For the hardening rule of the model, a hardening parameter $\kappa$ is established.

$$
d \kappa=\sqrt{d u_{n b o n d}^{p}+d u_{t b o n d}^{p}}
$$

The variables $\mu$ and $c$ in the yield functions are assumed to be functions of $\kappa$. The model can also be used for cyclic loading.

The model was validated against pull-out tests with various geometry and with both monotonic and cyclic loading; see Lundgren and Gylltoft. ${ }^{2}$ Furthermore, it was used in three-dimensional finite element analyses of different anchorage situations: lapped reinforcement splices, anchorage in beam-ends with varying support conditions, and anchorage at end regions of simply supported beams; see Lundgren and Magnusson. ${ }^{5}$ It was concluded that the model could describe the behaviour well, and reasonably good agreement was found between the analyses and the test results.

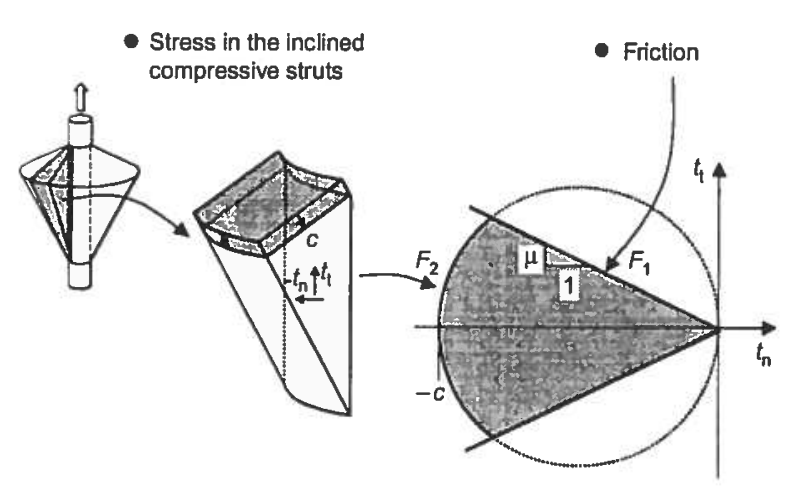

Fig. 2. The yield surface of the bond model

Magazine of Concrete Research, 2002, 54, No. 3 


\section{Chosen input for the bond model}

In Lundgren and Gylltoft, ${ }^{2}$ the bond model was calibrated for normal-strength concrete and reinforcement of type $\mathrm{K} 500 \phi 16$. The calibration was slightly modified here. In all the earlier analyses, slip between the reinforcement and the concrete appeared almost at once, and the normal stresses were almost solely due to the bond mechanism. When modelling the corrosion process, large normal stresses were applied to the bond layer, in some cases without any slip at all. As a consequence, parameters that previously had only minor effects on the behaviour became important. Two parameters were modified: the stiffness $D_{11}$ and the function $c(\kappa)$. The other input parameters were given as described in Lundgren and Gylltoft. ${ }^{2}$ That is, the coefficient of friction, $\mu$, was assumed to vary from 1.0 down to 0.4 during the hardening, and the parameter $\eta$ was assumed to be constant for monotonic loading.

In the previous work, the stiffness $D_{11}$ in equation (3) was assumed to be constant. Here, it was decided to let $D_{11}$ depend on the deformation $u_{n b o n d}$. This can physically be compared with the fact that normal pressure is obtainable only when there is contact between the two materials. If that rule were strictly followed, and penetration were not allowed, the stiffness $D_{11}$ would be zero for positive values of the normal deformation, and infinite when the normal deformation was zero. Such a definition of the stiffness would most likely lead to numerical problems. To reduce the problems, a maximum value of $D_{11}$ was chosen for $u_{\text {nbond }}$ smaller than zero, and $D_{11}$ was decreased for positive $u_{\text {nbond }}$ down to a minimum value, as shown in Fig. 3(a).

The hardening of the yield function $F_{2}$, i.e. the function $c(\kappa)$, was also modified. This function describes how the limiting stress in the inclined compressive struts varies with the hardening parameter $\kappa$. It was previously chosen to be the same as the uniaxial compression curve of the concrete, including a hardening part. However, since the chosen hardening parameter $\kappa$ is almost equivalent to the slip - see equation (7) - the cap will limit the normal stresses to the initial value of $c$ as long as no slip occurs. For a load case with only corrosion of a reinforcement bar, without any slip applied, splitting of the concrete can thus be prevented since the normal stresses are limited. This does not correspond to physical reality. Therefore, the function $c(\kappa)$ was changed so that only the descending part of the compressive stresses was taken into account, as shown in Fig. 3(b).

The analyses carried out by Lundgren and Gylltoft ${ }^{2}$ were re-run with this new calibration, and only minor effects on the results were found; see Lundgren. ${ }^{3}$

\section{Corrosion model}

Volume increase of the corrosion products

The volume increase of the corrosion products compared with the virgin steel was modelled in a corrosion layer. The volume of the rust relative to the uncorroded steel was given as input. Furthermore, the corrosion penetration $x$ was given as a function of the time. The corrosion was then modelled by taking time steps.

The physical interpretations of the variables of the model are presented in Fig. 4. By assuming that the volume of the rust (corresponding to the grey area in Fig. 4) is $v$ times the volume of the steel that has corroded (corresponding to the striped area in Fig. 4), the distance $a$ can be determined

$$
a=-r+\sqrt{r^{2}+(v-1) \cdot\left(2 r x-x^{2}\right)}
$$

This is the free increase of the radius; i.e. if the radius is increased that much, the normal stresses will be zero. The real increase of the radius is $u_{n c o r}$, corresponding to a strain in the rust

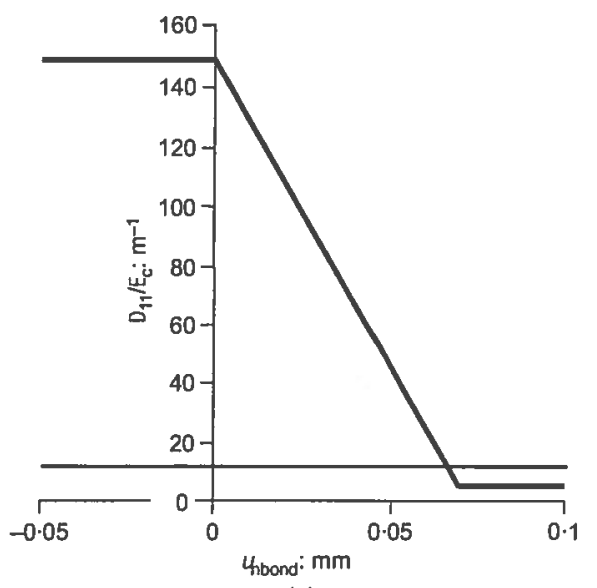

(a)

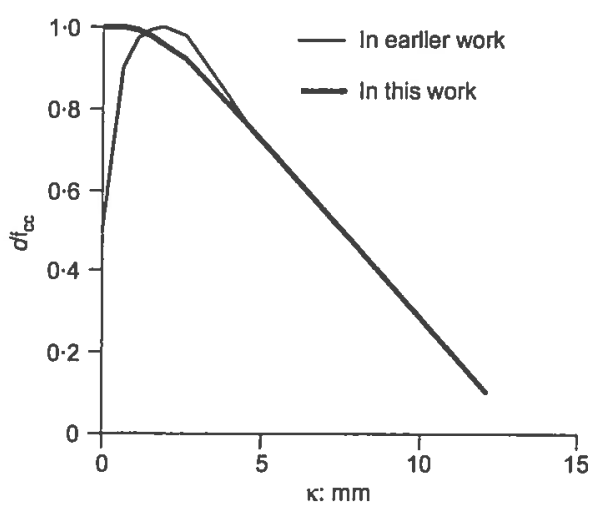

(b)

Fig. 3. (a) The stiffness; and (b) the function $c(k)$, in earlier work and as used in this article 


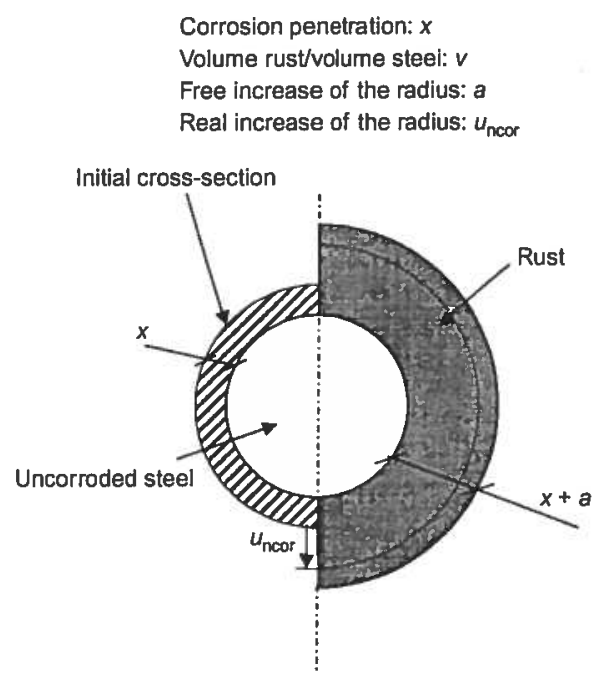

Fig. 4. Physical interpretation of the variables in the corrosion model

$$
\varepsilon_{\text {cor }}=\frac{u_{n c o r}-a}{x+a}
$$

From this strain in the rust, the normal stresses in the layer are determined; see the next section.

The volume of the rust relative to the uncorroded steel, $v$, is an important parameter in the model. This value depends on which corrosion product forms. Values from 2.2 to 6.4 are given in the literature; see Table 1. Most often, a value of 2.0 has been used in analyses of corrosion splitting; see Molina et al., Noghabai, ${ }^{8}$ and Coronelli and Gambarova. ${ }^{9}$ The latter value was also chosen here.

\section{Mechanical behaviour of the rust}

For the modelling of the corrosion layer, the mechanical behaviour of the corrosion products needs to be known. No information about this has been found in the literature. Molina et $a l^{7}$ assume that the rust is elastic but state that "the properties of the rust should be replaced by others which are more realistic if a way can be found to obtain them'. Petre-Lazar and Gerard ${ }^{10}$ used a scratching test to investigate the mechanical properties of the corrosion products. They reached the conclusion that rust is a cohesionless assemblage of incompressible crystals.

To investigate the mechanical behaviour of rust, corrosion cracking tests found in the literature were studied. In all of these, corrosion was induced by an

Table 1. The volume of the rust relative to the uncorroded steel $^{6}$

\begin{tabular}{l|c}
\hline Corrosion product & Volume increase \\
\hline $\mathrm{Fe}_{3} \mathrm{O}_{4}$ & $2 \cdot 2$ \\
$\mathrm{Fe}(\mathrm{OH})_{2}$ & $3 \cdot 8$ \\
$\mathrm{Fe}(\mathrm{OH})_{3}$ & $4 \cdot 2$ \\
$\mathrm{Fe}(\mathrm{OH})_{3}, 3 \mathrm{H}_{2} \mathrm{O}$ & $6 \cdot 4$ \\
\hline
\end{tabular}

impressed current. Ghandehari et al. ${ }^{11}$ have carried out pull-out tests on corroded reinforcement bars in concrete cylinders. Al-Sulaimani et al. ${ }^{12}$ and Cabrera and Ghoudoussi ${ }^{13}$ have carried out pull-out tests on corroded reinforcement bars concentrically placed in concrete blocks. To investigate the mechanical behaviour of rust, the first part of their experiments was studied, i.e. when the reinforcement corroded until the specimen was cracked. The corrosion penetration was measured by the weight loss method; from these measurements the corrosion penetration at cracking can be estimated. Axisymmetric finite element analyses of the test specimens were carried out. For the tests of Ghandehari et $a l .^{11}$ this corresponds to the geometry of the test specimen, and for the others it was accepted as a reasonable approximation. Only the concrete was then modelled, and a normal stress was applied at the hole in the centre of the cylinder; see Fig. 5(a). The concrete was modelled with a constitutive model based on non-linear fracture mechanics, and four radial cracks were assumed. For more details of how the concrete was modelled, see the section 'Finite element analyses' in 'Comparison with tests'. The results from some of the analyses are shown in Fig. 5(b), where the deformation at the hole of the concrete cylinder is plotted versus the applied normal stress.

Andrade et $a l^{14}$ carried out corrosion cracking tests with reinforcement bars eccentrically placed in concrete blocks. Due to this placement, an axisymmetric approximation was not possible. Instead, two-dimensional models assuming plane strain were used; see one example in Fig. 6. The normal stress was applied in the hole both with deformation control and with load control. In reality, there would be deformation control if the corrosion products behave very stiffly; else the deformation around the hole would differ slightly. The different ways to apply the load gave approximately the same results. It was chosen to use the results from the deformation-controlled analyses, with the normal stress as the one applied where the crack appeared. In Table 2, the main results from all analyses are tabulated.

Since the Young's modulus is much larger for the steel than for the concrete, it can be assumed that the deformation of the reinforcement bar is negligible. The stiffness in the normal direction of the bond layer, $D_{11}$, is chosen large enough that the deformation of the bond layer is also negligible. Thereby, it can be concluded that the deformation of the concrete cylinder approximately equals the deformation in the corrosion layer, $u_{\text {ncor }}$.

By combining the obtained $u_{n c o r}$ with the corrosion penetration at cracking from the experiments, a value of the strain in the rust can be calculated, using equation (8) and equation (9), with the chosen value of 2.0 for the volume of the rust relative to the uncorroded steel. The results from the tests and analyses are summarised in Table 2, and in Fig. 7 the normal stress

Magazine of Concrete Research, 2002, 54, No. 3 


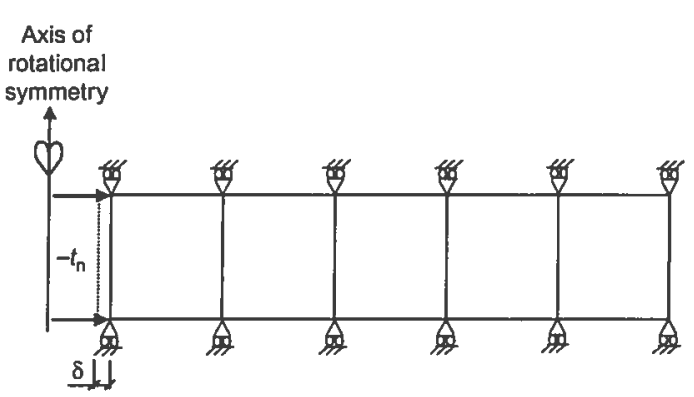

(a)

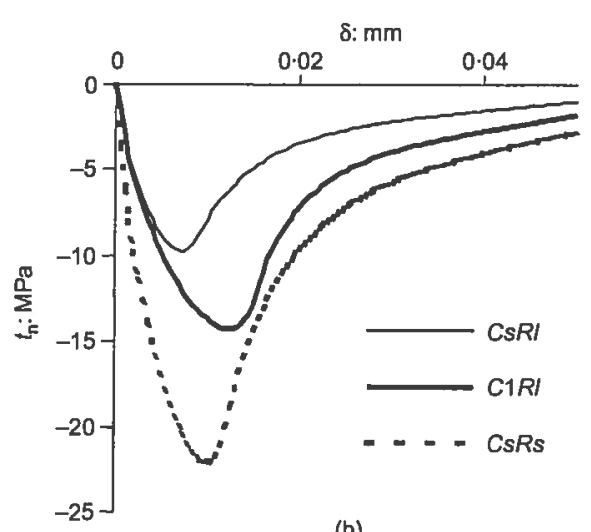

(b)

Fig. 5. (a) Axisymmetric finite element analyses of a concrete cylinder, with a normal stress applied at the hole in the centre of the cylinder; (b) results from such analyses: the normal stress versus the deformation at the hole of the concrete cylinder

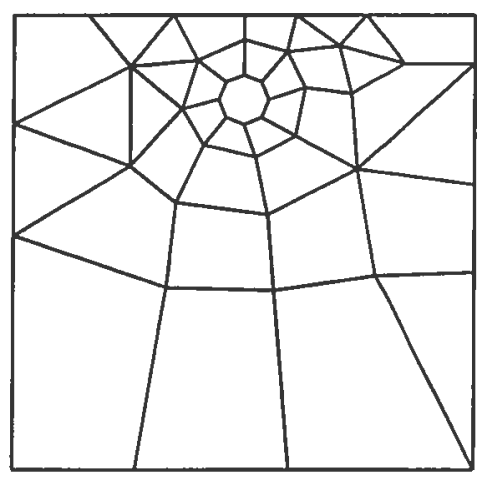

Fig. 6. Two-dimensional model of test II of Andrade et al. ${ }^{14}$ for estimation of the mechanical behaviour of the corrosion products

versus the strain in the rust is plotted. Although it must be noted that parameters known to have an influence on cracking - such as the applied current - varied for the tests analysed, this can give some information about

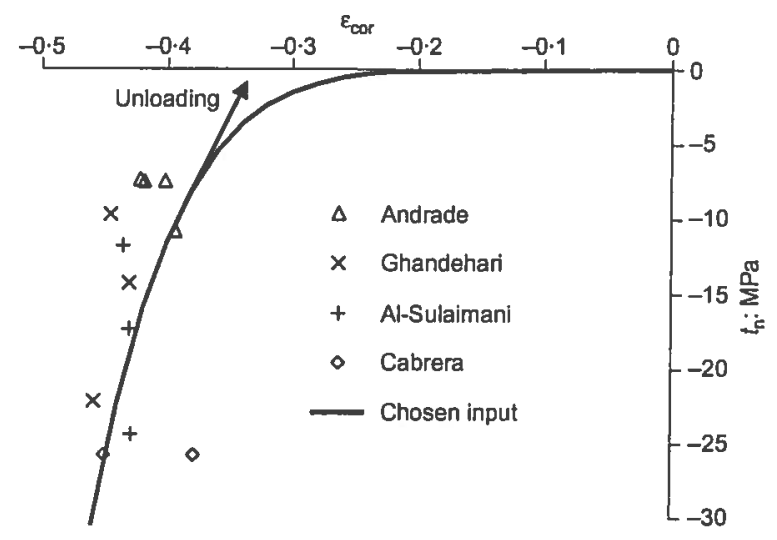

Fig. 7. Normal stress versus strain in the rust evaluated from a combination of experimental results and analyses, together with the chosen input

the mechanical behaviour of the rust. The results indicate that the rust does not have a linear elastic behaviour. Instead, it was assumed that the rust behaves like a granular material; i.e. its stiffness increases with the

Table 2. Evaluation of normal stress and strain in the rust

\begin{tabular}{|c|c|c|c|c|c|c|c|}
\hline Reference & $\begin{array}{l}\text { Test } \\
\text { No. }\end{array}$ & $\begin{array}{c}\text { Concrete } \\
\text { cover } \\
(\mathrm{mm})\end{array}$ & $\begin{array}{l}\text { Rebar } \\
\text { diameter } \\
\text { (mm) }\end{array}$ & $\begin{array}{c}x \text { at cracking, } \\
\text { from exp. } \\
(\mu \mathrm{m})\end{array}$ & $\begin{array}{c}u_{\text {ncor }} \text { at cracking, } \\
\text { from analyses } \\
(\mathrm{mm})\end{array}$ & $\begin{array}{c}t_{n} \text { at cracking, } \\
\text { from analyses } \\
(\mathrm{MPa})\end{array}$ & $\begin{array}{c}\varepsilon_{c o r} \text { at cracking, } \\
\text { from equations (8) } \\
\text { and (9) }\end{array}$ \\
\hline \multirow[t]{3}{*}{ Ghandehari et al. $^{11}$} & CsRs & 45 & 9.5 & 159 & 0.0105 & $-22 \cdot 2$ & -0.458 \\
\hline & CsRl & 40 & 20 & 72 & 0.0075 & -9.80 & -0.446 \\
\hline & $C I R I$ & 65 & 20 & 92 & 0.0125 & $-14 \cdot 3$ & -0.429 \\
\hline \multirow[t]{2}{*}{ Cabrera and Ghoddoussi ${ }^{13}$} & opc & 69 & 12 & 68 & 0.016 & $-25 \cdot 8$ & -0.378 \\
\hline & pfa & 69 & 12 & 192 & 0.016 & $-25 \cdot 8$ & -0.450 \\
\hline \multirow[t]{3}{*}{ Al-Sulaimani et al. ${ }^{12}$} & & 70 & 10 & 115 & 0.015 & $-24 \cdot 5$ & -0.428 \\
\hline & & 68 & 14 & 102 & 0.0133 & $-17 \cdot 3$ & -0.430 \\
\hline & & 65 & 20 & 93 & 0.0115 & $-11 \cdot 8$ & -0.435 \\
\hline \multirow[t]{4}{*}{ Andrade et al. ${ }^{14}$} & I & 20 & 16 & $17 \cdot 9$ & 0.0028 & $-7 \cdot 37$ & -0.421 \\
\hline & 11 & 20 & 16 & 14.4 & 0.0028 & $-7 \cdot 50$ & -0.402 \\
\hline & 111 & 30 & 16 & $21 \cdot 3$ & 0.0045 & -10.08 & -0.394 \\
\hline & IV & 20 & 16 & $17 \cdot 4$ & 0.0028 & $-7 \cdot 50$ & -0.419 \\
\hline
\end{tabular}


stress level. This also corresponds to the findings of Petre-Lazar and Gerard ${ }^{10}$ that rust is a cohesionless assemblage of incompressible crystals. It was assumed that the mechanical behaviour of the rust at loading could be described with the equation

$$
t_{n}=K_{c o r} \cdot \varepsilon_{c o r}^{p}
$$

The parameters $K_{\text {cor }}$ and $p$ were chosen to give reasonable agreement with the results from the analyses of the tests; see Fig. 7, where the curve for the chosen values of $K_{\text {cor }}=7.0 \mathrm{GPa}$ and $p=7.0$ is plotted together with the analysis results. Further, it was assumed that the rust was unloaded with the stiffness achieved, as indicated in Fig. 7.

\section{Discussion of the corrosion model}

The effect of the corrosion is modelled here only as a volume increase of the corrosion products compared with the virgin steel. In the literature, it is often claimed that corrosion of reinforcement bars also decreases the friction between the reinforcement and the concrete, see for example FIB. ${ }^{1}$ However, in all tests of the bond mechanism of corroded reinforcement found in the literature, only the bond stress and the slip have been measured. The normal stress in the bond mechanism, or the effect of the normal stress, have not been measured. Therefore, how the friction coefficient between the reinforcement and the concrete is affected by corrosion of the bar is difficult to evaluate. For deformed bars, it seems likely that the friction will remain approximately the same as long as the corrosion does not remove large parts of the ribs. Here, it was thus decided not to take this influence into account. For large corrosion penetrations, or for smooth bars, this decision probably needs to be reconsidered.

The lack of information about the mechanical behaviour of the corrosion products is of course annoying. To use a combination of test results and analyses as done in this paper might be one approach. However, as pointed out by Petre-Lazar and Gerard, ${ }^{10}$ it may be possible for the rust to fill up the pores close to the reinforcement bars before starting to apply stresses in the structure. With the present method, this will be included in the mechanical behaviour of the corrosion products. Hence their behaviour will be influenced by properties of the concrete, such as the porosity. This can be reasonable, since the properties of the concrete may influence what type of corrosion product is formed, and thereby its mechanical behaviour. On the other hand, if it is believed that the same corrosion products will form, their behaviour should not be affected by the properties of the concrete. However, as the mechanical behaviour of the corrosion products was not been obtained in another way, the present method was chosen.

\section{Comparison with tests}

\section{Finite element analyses}

Tests of various kinds with corroding reinforcement have been analysed with finite element models. In all analyses, the concrete was modelled with a constitutive model based on non-linear fracture mechanics. In analyses using the smeared crack concept, a rotating crack model based on total strain was used; see TNO. ${ }^{15}$ For the axisymmetric models, four discrete radial cracks were assumed.

From the various measured compressive strengths, an equivalent compressive cylinder strength, $f_{c c}$, was evaluated. Other necessary material data for the concrete were estimated according to the expressions in $\mathrm{CEB}^{16}$ from $f_{c c}$. The constitutive behaviour of the reinforcement steel was modelled by the Von Mises yield criterion with associated flow and isotropic hardening. The elastic modulus of the reinforcement was assumed to be $200 \mathrm{GPa}$.

\section{Corrosion cracking tests}

Andrade et al. ${ }^{14}$ have carried out corrosion cracking tests, briefly described in the section 'Mechanical behaviour of the corrosive products'. These were analysed with three-dimensional models, using the presented corrosion and bond model in interface elements between the reinforcement and the concrete. In the tests, the specimens were $15 \mathrm{~cm} \times 15 \mathrm{~cm} \times 38 \mathrm{~cm}$. Here, slices of them were analysed, assuming fixed boundaries in the third direction, corresponding to a plane strain assumption. At first, analyses using a smeared crack model were carried out. However, it was noted that after cracking, tensile stresses of about twice the tensile strength of the concrete were obtained, even though a rotating crack model was used. This stress locking has been explained by Rots. ${ }^{17}$ Although different meshes were tried, this phenomenon could not be avoided. Furthermore, while the different meshes resulted in cracking at about the same levels, the crack opening differed quite a lot between the analyses.

Therefore, it was chosen to model the cracks with discrete crack elements instead. Then, only the tests with the reinforcement bar placed in a symmetry line were modelled, since the crack pattern was easier to predict for that case. One of the finite element models is shown in Fig. 8(a). In Figs 8(b)-(d), comparisons between measured crack widths and crack widths obtained in the analyses are shown. As can be seen, the crack openings in the analyses are somewhat too small. One reason for this might be that the corrosion penetration was obtained in the tests by the use of Faraday's law. Later tests by Alonso et al. ${ }^{18}$; where they measured the corrosion penetration also by the weight loss method, indicated that the corrosion penetration was underestimated by Faraday's law. On this basis, the results from the experiments should be moved towards larger corrosion penetration, i.e. to the right in Fig. 8, 


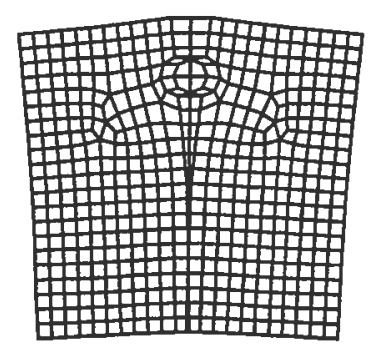

(a)

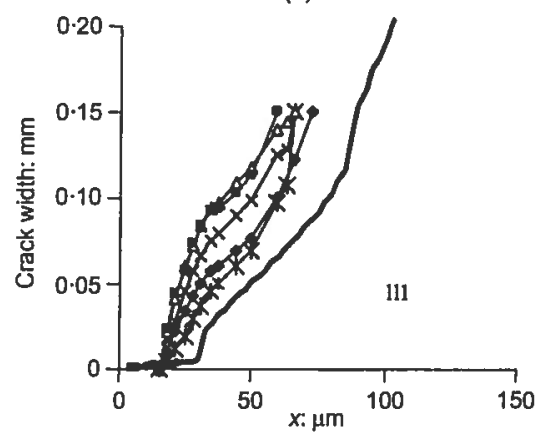

(c)
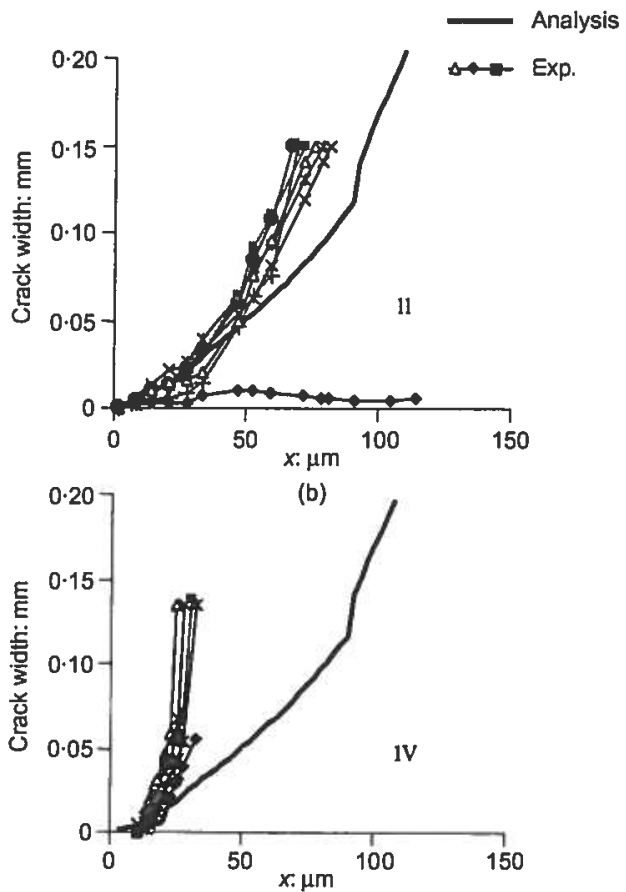

(d)

Fig. 8. (a) Deformed mesh in analysis of test II using the bond and corrosion models in the interface elements between the steel and the concrete; (b)-(d) comparisons between crack widths, measured and obtained in the analyses, versus the corrosion penetration. Experimental results from Andrade et al. ${ }^{14}$

thus leading to improved agreement. Another reason can be that the factor 2.0 used for the volume of the rust relative to the uncorroded steel is too small, see Table 1.

\section{Pull-out tests}

The pull-out tests on corroded reinforcement bars in concrete cylinders carried out by Ghandehari et al. ${ }^{11}$ have been analysed. They used four different geometries: with cylinder diameters of 100 and $150 \mathrm{~mm}$, and with rebar diameters of 9.5 and $20 \mathrm{~mm}$. These were labelled $C_{s} R s, C s R l, C l R s$ and $C l R l$, where $C$ stands for the concrete cylinder diameter, $R$ for the rebar diameter, and $s$ and $l$ for small and large. The specimens were $50 \mathrm{~mm}$ slices, and were subjected to accelerated constant current corrosion for 4 weeks. The rebar in each slice was tested in pull-out to investigate the bond strength after $0,1,2,3$ and 4 weeks of corrosion. The corrosion penetration was evaluated both by using Faraday's law from the applied current, and by measuring the weight loss for the reinforcement in each slice. Here, the measured corrosion penetration (evaluated from the weight loss) was used as input.

Axisymmetric finite element analyses were carried out, with the specially developed interface elements describing the corrosion of the reinforcement bar and the bond mechanism. The finite element mesh used for the analyses of specimen $C_{S} R s$ is shown in Fig. 9. In the analyses, the corrosion was first applied as time

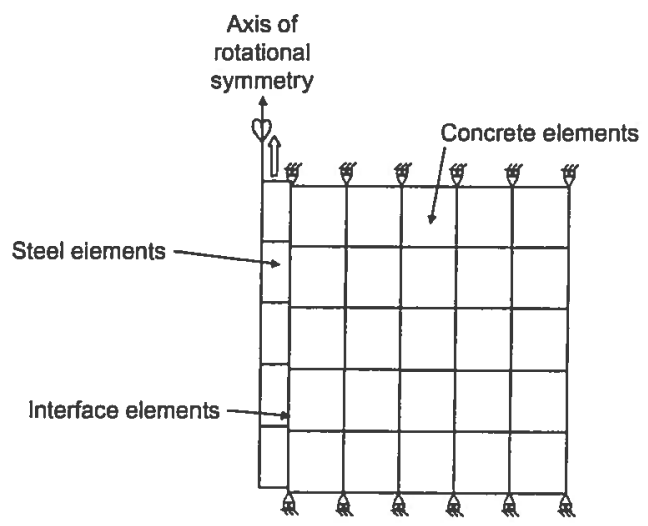

Fig. 9. The finite mesh used for the analyses of specimen CsRs

steps. When the corrosion penetration measured in the experiments was reached, the reinforcement bar was pulled out of the concrete cylinder. In order to get stable solutions if cracking occurred only for the corrosion attack, the deformations of both the upper and the lower nodes of the concrete cylinder were tied as shown in Fig. 9. In the analyses, only the failure of ClRs was a pull-out failure, while all the other three were splitting failures, both for the uncorroded pull-out and for the pull-out tests after corrosion. It is not described by Ghandehari et al. ${ }^{11}$ which type of failure occurred in 
the experiments. However, since the capacity of specimen ClRs was slightly increased when the reinforcement had corroded, while for the others it was decreased, pull-out failure of specimen ClRs and splitting failure of the others was most likely the case also for the tests.

From each of the pull-out analyses, the maximum load was compared with the maximum load obtained when the reinforcement was uncorroded. In Fig. 10, a comparison between the measured bond strengths and those from the analyses is shown. The corrosion penetration when cracking penetrated the cover is also marked. Only one minor difference between the experimental and analytical results can be noted: that the maximum capacity is not increased for small corrosion penetration in the analyses of the ClRs specimen, as it was in the tests. Otherwise, the agreement between the tests and the analyses is good.

\section{Conclusions}

The mechanical behaviour of rust was studied by a combination of analyses with test results found in the literature. This led to the assumption that rust behaves like a granular material, i.e. its stiffness increases with the stress level. This mechanical behaviour, and the volume increase of the corrosive products compared with the virgin steel, were modelled in a corrosion layer. The corrosion layer was combined with a previously developed model of the bond mechanism. This bond model includes the splitting stresses of the bond action, and is sensitive to the strength of the surrounding structure. By combining these models, the effect of corrosion on the bond strength can be analysed for diverse structures, and the effect of varying cover, stirrups, outer pressure, etc., can be investigated.

Comparisons between analyses of corrosion cracking tests and test results found in literature indicate reasonable agreement. Furthermore, pull-out tests with corroded reinforcement bars were analysed. The results show that this method of modelling can predict the decrease of bond when splitting of the concrete occurs, due to the combined action of corrosion and the bond mechanism.

Here, tests with accelerated corrosion have been analysed. In order to investigate the effect of corrosion in real structures, long-term effects such as creep and shrinkage of the concrete must probably be included in the analyses, as pointed out by Noghabai. ${ }^{8}$ Furthermore, the corrosion attack penetration has been given as a function of the time as input in the analyses. In
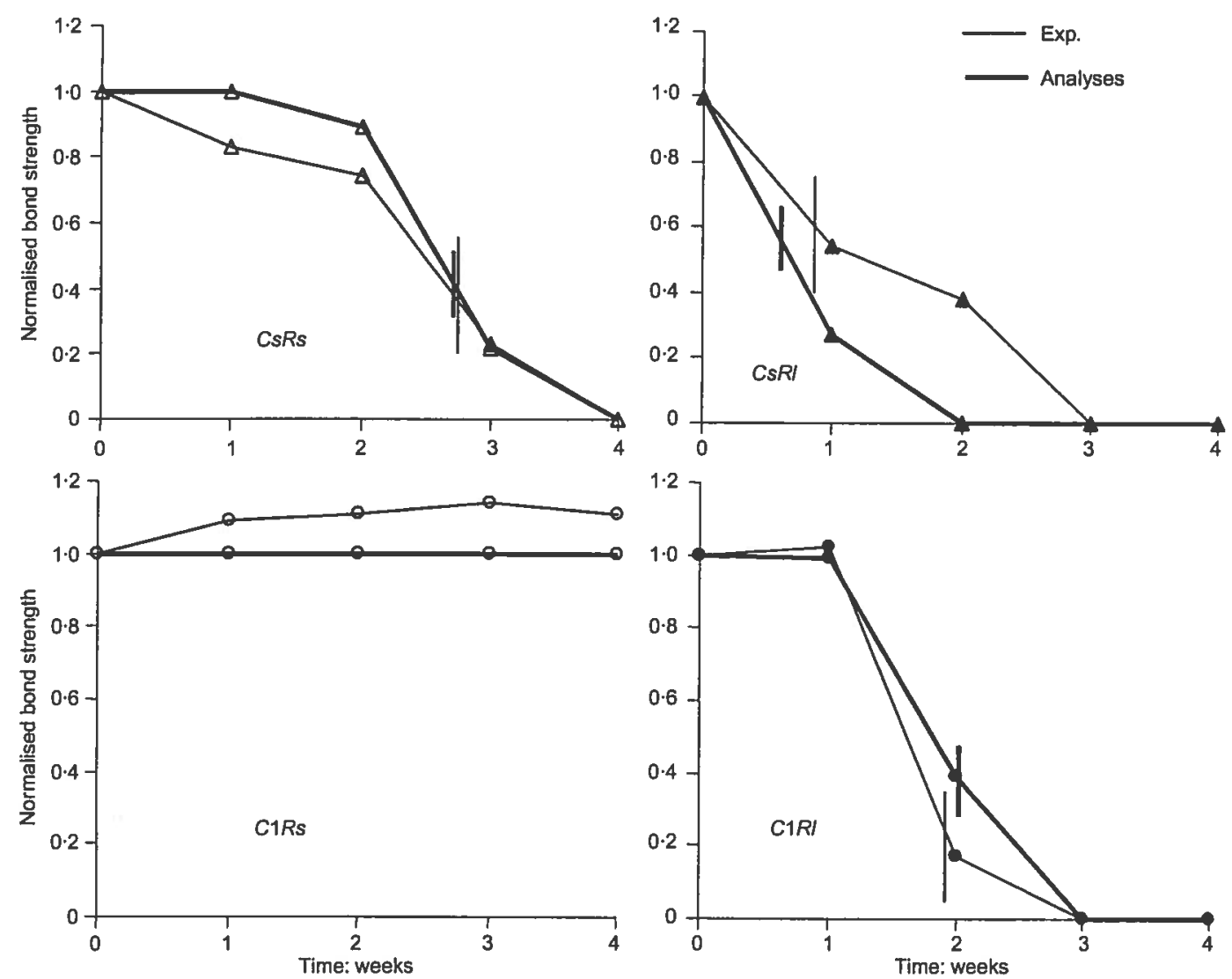

Fig. 10. Comparisons between normalised bond strength, measured and obtained in the analyses versus the time. The vertical lines indicate when cracking penetrated the cover. Experimental results from Ghandehari et al. "I 
future research, it would be most interesting to include this time-dependence in the analysis so that various environments, concrete cover and cracking could influence the corrosion rate and volume increase. Thereby, it would be possible to investigate a structure's lifetime and to determine the effect of various environments on, for example, the structure's deformations and loadbearing capacity.

\section{References}

1. FIB (International Federation for Structural Concrete). Bond of reinforcement in concrete. State-of-art report prepared by Task Group Bond Models, FIB bulletin 10, Lausanne 2000.

2. LUNDGREN K. and GYLLTOFT K. A model for the bond between concrete and reinforcement. Magazine of Concrete Research, 2000, 52, No. 1, 53-63.

3. LUNDGREN K. Bond between Corroded Reinforcement and Concrete. Chalmers University of Technology, Department of Structural Engineering, Concrete Structures, Report 00:3, Göteborg 2001 .

4. LUNDGREN K. Three-dimensional Modelling of Bond in Reinforced Concrete: Theoretical Model, Experiments and Applications. $\mathrm{PhD}$ thesis, Chalmers University of Technology, Division of Concrete Structures, Publication 99:1, Göteborg, 1999.

5. LUNDGREN K. and MAGNUSSON J. Three-dimensional modelling of anchorage zones in reinforced concrete. ASCE Journal of Engineering Mechanics, 2001, 127, 693-699.

6. TuUTTI K. Corrosion of Steel in Concrete. Swedish Cement and Concrete Research Institute, 1982.

7. Molina F. J., Alonso C. and ANDRADE C. Cover cracking as a function of rebar corrosion: Part 2 - Numerical model. Materials and Structures, 1993, 26, 532-548.

8. NOGHABAI K. Effect of Tension Softening on the Performance of Concrete Structures. PhD thesis 1998:21, Division of Structural Engineering, Luleå University of Technology, Luleả, 1998.
9. Coronelli D. and Gambarova P. G. A mechanical model for bond strength of corroded reinforcement in concrete. In Proceedings EM2000, Fourteenth Engineering Mechanics Conference, ASCE, Austin, Texas, USA, May 2000.

10. Petre-Lazar I. and Gerard B. Mechanical behaviour of corrosion products formed at the steel-concrete interface. Testing and modelling. In Proceedings EM2000, Fourteenth Engineering Mechanics Conference, ASCE, Austin, Texas, USA, May 2000.

11. GHANDEhari M., Zulli M. and ShaH S. P. Influence of cortosion on bond degradation in reinforced concrete. In Proceedings EM2000, Fourteenth Engineering Mechanics Conference, ASCE, Austin, Texas, USA, May 2000.

12. Al-Sulaimani G. J., Kaleemullah M., Basunbul I. A. and RASHEEDUZZAFAR. Influence of corrosion and cracking on bond behaviour and strength of reinforced concrete members. $A C I$ Structural Journal, 1990, 87, No. 2, 220-231.

13. Cabrera J. G. and Ghoddoussi P. The effect of reinforcement corrosion on the strength of the steel/concrete 'bond'. In Bond in Concrete, Proceedings of an International Conference, CEB, Riga, 1992.

14. ANDRADE C., Alonso C. and Molina F. J. Cover cracking as a function of bar corrosion: Part 1-Experimental test. Materials and Structures, 1993, 26, 453-464.

15. TNO Building and Construction Research. DIANA Finite Element Analysis, User's Manual release 7, Hague 1998.

16. CEB. CEB-FIP Model Code 1990, CEB Bulletin d'Information No. 213/214, Lausanne 1993.

17. Rots J. G. Computational Modeling of Concrete Fracture. Department of Civil Engineering, Delft University of Technology, 1988.

18. Alonso C., Andrade C., Rodriguez J. and Diez J. M. Factors controlling cracking of concrete affected by reinforcement corrosion. Materials and Structures, 1998, 31, Aug-Sept, $435-441$.

Discussion contributions on this paper should reach the editor by 13 November 2002 